\title{
Laminar-Specific Maturation of GABAergic Transmission and Susceptibility to Visual Deprivation Are Related to Endocannabinoid Sensitivity in Mouse Visual Cortex
}

\author{
Bin Jiang, ${ }^{1}$ Kazuhiro Sohya, ${ }^{1}$ Abdolrahman Sarihi, ${ }^{1}$ Yuchio Yanagawa, ${ }^{2,3}$ and Tadaharu Tsumoto ${ }^{1}$ \\ ${ }^{1}$ Brain Science Institute, RIKEN, Wako 351-0198, Japan, ${ }^{2}$ Department of Genetic and Behavioral Neuroscience, Graduate School of Medicine, \\ Gunma University, Maebashi 371-8511 Japan, and 3Japan Science and Technology Agency, Core Research for Evolutional Science and Technology, \\ Tokyo 102-0075 Japan
}

\begin{abstract}
The developmental period when neuronal responses are modified by visual experience is reported to start and end earlier in layer 4 than in layer $2 / 3$ of the visual cortex, and the maturation of GABAergic inhibitory circuits is suggested to determine the timing of this period. Here, we examine whether the laminar difference in such timing corresponds to a difference in the time course of the functional maturation of GABAergic synaptic transmission to star pyramidal and pyramidal cells in layers 4 and $2 / 3$, respectively, of the mouse visual cortex and whether the development of the strength of GABAergic transmission is affected by visual deprivation in a laminar-specific manner. Our analysis of developmental changes in inhibitory postsynaptic currents of star pyramidal and pyramidal cells evoked by electrical stimulation of afferents or action potentials of fast-spiking GABAergic neurons revealed that there was a sequential maturation of GABAergic function from layers 4 to $2 / 3$. The maturation of inhibition in layer 4 occurred at postnatal week 3 , which preceded by 1 week that of layer $2 / 3$. Visual deprivation by dark rearing arrested the functional development of GABAergic transmission in layer $2 / 3$, whereas dark rearing was not so effective in layer 4. GABAergic synapses in layer $2 / 3$ were sensitive to an agonist for cannabinoid type 1 receptors and not normally matured in receptor knock-out mice, whereas those in layer 4 were not so. These results suggest laminar-specific maturation of inhibition and susceptibility to visual deprivation, which may be related to the laminar difference in sensitivity to endocannabinoids.
\end{abstract}

\section{Introduction}

In the visual cortex, the binocular visual responsiveness of cortical neurons is modified by monocular visual deprivation during the so-called critical period of postnatal development (Wiesel and Hubel, 1963; Daw, 1995). The visual cortex is a laminated structure so that neurons in different layers may have different properties of such ocular dominance plasticity. In fact, it was reported that the effect of monocular deprivation starts and terminates earlier in layer 4 than in other layers of the cat visual cortex (Daw et al., 1992), and ocular dominance plasticity in layer 4 is much weaker than that in extragranular layers of the mouse visual cortex (Gordon and Stryker, 1996). Furthermore, in layer $2 / 3$ of the cortex, the ocular dominance plasticity remains to a substantial extent in juvenile or even fully mature animals (Daw et al., 1992; Guire et al., 1999; Sawtell et al., 2003; Pham et al., 2004; Sato and Stryker, 2008).

There is a similar laminar difference in another form of plasticity, long-term potentiation (LTP) and long-term depression

Received June 10, 2010; revised Aug. 10, 2010; accepted Aug. 21, 2010.

This work was supported in part by a Grant-in-Aid for Scientific Research from the Japan Society for the Promotion of Science to TT (19300117). We thank Drs. A. Kirkwood and A. Weitemier for critically reading this manuscript, Dr. A. Miyawaki for providing pCS2-Venus, Dr. W. Bai for assisting in part of the experiments, and Dr. M. Kano for providing cannabinoid type 1 receptor knock-out mice.

Correspondence should be addressed to either Dr. Tadaharu Tsumoto or Dr. Bin Jiang at Brain Science Institute, RIKEN, 2-1 Hirosawa, Wako 351-0198, Japan. E-mail: tsumoto@brain.riken.jp or bjiang@brain.riken.jp.

DOI:10.1523/JNEUROSCI.2979-10.2010

Copyright $\odot 2010$ the authors $\quad 0270-6474 / 10 / 3014261-12 \$ 15.00 / 0$
(LTD) of synaptic transmission. In star pyramidal cells in layer 4 of the visual cortex, LTP and LTD of excitatory synapses become uninducible shortly after eye opening, whereas in pyramidal neurons in layer $2 / 3$ these forms of synaptic plasticity still persist beyond puberty (Kirkwood et al., 1995; Dudek and Friedlander, 1996; Heynen and Bear, 2001; Jiang et al., 2007). Although previous studies on the laminar difference in LTP and LTD were limited to excitatory synapses, the reported results suggest that the developmental time window for plasticity in layer 4 may be quite different from that in layer $2 / 3$.

The development of the strength of intracortical GABAergic inhibition to the critical threshold is suggested to be a requirement for triggering ocular dominance plasticity (Hensch et al., 1998) (for review, see Hensch, 2005; Jiang et al., 2005). The observations that dark rearing (DR) attenuates the developmental decline in ocular dominance plasticity (Cynader and Mitchel, 1980; Cynader, 1983; Fagiolini et al., 1994) suggest that visual experience plays a role in the maturation of intracortical GABAergic circuitry (Morales et al., 2002; Jiang et al., 2005). However, questions of whether the laminar difference in the time window for plasticity corresponds to a difference in the time course of maturation of GABAergic transmission to principal neurons in the cortex and whether developmental changes in the strength of GABAergic synapses in different laminae are affected by dark rearing in a differentiated manner still remain unanswered. A recent finding that endocannabinoid-mediated LTD is necessary for this maturation process in layer $2 / 3$ of the visual 
cortex (Jiang et al., 2010) further raises a question of whether endocannabinoids are involved in the laminar-specific maturation process. Our results demonstrate that the maturation of inhibition in layer 4 preceded by 1 week that in layer $2 / 3$, and the developmental enhancement of inhibition in layer $2 / 3$ was arrested by dark rearing, whereas it was less susceptible in layer 4 , and suggest that this difference may be related to the laminar difference in endocannabinoid sensitivity during postnatal development.

\section{Materials and Methods}

Slice preparations. Coronal slices of the visual cortex (300 $\mu \mathrm{m}$ thick) were prepared from C57BL/6J mice, vesicular GABA transporterVenus transgenic mice (VGAT-Venus mice), or the type 1 of cannabinoid receptor knockout (CB1-KO) mice, aged at postnatal day 10 (P10)-P42, using a tissue slicer (Vibratome 3000; Vibratome) in ice-cold dissection buffer containing the following (in $\mathrm{mm}$ ): 212.7 sucrose, $5 \mathrm{KCl}, 1.25 \mathrm{NaH}_{2} \mathrm{PO}_{4}, 3 \mathrm{MgCl}_{2}, 1 \mathrm{CaCl}_{2}$, $26 \mathrm{NaHCO}_{3}$, and 10 dextrose, bubbled with $95 \% \mathrm{O}_{2} / 5 \% \mathrm{CO}_{2}$. The mice older than $\mathrm{P} 14$ were male, although those younger than P12 were not identified as male or female. VGATVenus transgenic mice were generated as reported previously (Wang et al., 2009) and confirmed to express the normal level of the GABA synthesizing enzyme, glutamate decarboxylase 67 (Kameyama et al., 2010). In part of the experiments, we used CB1-KO mice. Breeding pairs of CB1-KO mice that have been backcrossed to the C57BL/6J strain were provided by Dr. M. Kano (Graduate School of Medicine, University of Tokyo, Japan) (Kishimoto and Kano, 2006) with permission of Dr. A. Zimmer (Molecular Neurobiology, University of Bonn, Bonn, Germany) (Zimmer et al., 1999). The CB1-KO mice $\left(\mathrm{CB1}^{-/-}\right)$and their littermate controls $\left(\mathrm{CB1}^{+/+}\right)$were obtained by mating heterozygous $\left(\mathrm{CB1} 1^{+/-}\right)$breeding pairs. Genotypes of the mice were determined using tail biopsies and DNA PCR

The slices were transferred to artificial CSF (ACSF) for $>1 \mathrm{~h}$ before recording. ACSF was similar to the dissection buffer except that sucrose was replaced with $124 \mathrm{~mm} \mathrm{NaCl}, \mathrm{MgCl}_{2}$ was $1 \mathrm{~mm}$, and $\mathrm{CaCl}_{2}$ was $2 \mathrm{~mm}$. All the recordings were performed at $31^{\circ} \mathrm{C}$. Star pyramidal cells in layer 4 and pyramidal cells in layer $2 / 3$ were identified visually under infrared differential interference contrast optics on the basis of their pyramidal somata and prominent apical dendrites as described previously (Jiang et al., 2007). Their morphological identification was further confirmed by biocytin staining after recording. All of the experimental procedures were performed in accordance with the guidelines of the Animal Experiments Committee of RIKEN Brain Science Institute.

Evoked postsynaptic current recordings. Evoked EPSCs (eEPSCs) and evoked IPSCs (eIPSCs) were recorded from pyramidal cells in layer $2 / 3$ or star pyramidal cells in layer 4 by the whole-cell voltage-clamp method. A concentric bipolar stimulating electrode with a tip diameter of $125 \mu \mathrm{m}$ was placed either in layer 4 or the underlying white matter to evoke synaptic responses of neurons in layer $2 / 3$ or layer 4 , respectively. Patch pipettes (2-4 $\mathrm{M} \Omega$ ) were filled with the internal solution consisting of the following (in $\mathrm{mm}$ ): 120 Cs-methylsulfonate, $20 \mathrm{KCl}, 10 \mathrm{HEPES}, 10 \mathrm{Na}$-phosphocreatine, 5 lidocaine $N$-ethyl bromide (QX-314), 4 ATP, 0.5 GTP, and $0.2 \%$ biocytin, $\mathrm{pH} 7.4$. The osmolarity of the solution was $270-285 \mathrm{mOsm}$. The eEPSCs and eIPSCs were recorded from the same cells by changing their membrane potentials sequentially to the reversal potentials for GABAergic inhibition and glutamatergic excitation, respectively (Maffei et al., 2004). To isolate combined AMPA/NMDA receptor-mediated currents, neurons were held at the reversal potential for $\mathrm{GABA}_{\mathrm{A}}$ receptor-mediated currents. To isolate $\mathrm{GABA}_{\mathrm{A}}$ receptor-mediated currents, neurons were held at the reversal potential for AMPA/NMDA receptor-mediated currents. The reversal potentials for each neuron were determined by holding the membrane potential from -50 to $-30 \mathrm{mV}$ in $5 \mathrm{mV}$ increments for $\mathrm{GABA}_{\mathrm{A}}$ receptors and from 0 to $+15 \mathrm{mV}$ in $5 \mathrm{mV}$ increments for AMPA/NMDA receptors. The stimulus intensity was changed systematically $(5,10,15,20,25,30,40,60$, and $80 \mu \mathrm{A})$ for pulses of $0.1 \mathrm{~ms}$ width. Interstimulus intervals were $>15 \mathrm{~s}$ to minimize depression resulting from repetitive stimulation, and at least 10 responses for each intensity were averaged to measure the properties of EPSCs and IPSCs. In part of the experiments, DL-2-amino-5-phosphonovaleric acid (APV; Sigma-Aldrich), an NMDA receptor antagonist, at $100 \mu \mathrm{M}$ and 6-cyano-7nitroquinoxaline-2,3-dione (CNQX; Sigma-Aldrich), an AMPA receptor antagonist, at $20 \mu \mathrm{M}$ were added to the ACSF to directly record monosynaptic IPSCs to exclude the possibility of the contribution of polysynaptic recruitment to synaptic inhibition. In experiments in which we attempted to isolate eISPCs from fast-spiking GABAergic (FS-GABA) neurons, conotoxin (Ctx; Sigma-Aldrich) at $300 \mathrm{~nm}$ was used to block the N-type voltagedependent $\mathrm{Ca}^{2+}$ channels that are known to mediate GABA release from non-FS interneurons (Wilson et al., 2001; Zaitsev et al., 2007).

Unitary IPSC recordings. Dual whole-cell recordings were performed to measure the strength and dynamics of monosynaptic connections from FS-GABA neurons to pyramidal cells and star pyramidal cells within layers $2 / 3$ and 4 of the visual cortex, respectively. In these experiments, VGAT-Venus mice in which GABAergic neurons can be identified under a fluorescence microscope (BX51WI; Olympus) were used to facilitate paired recordings from GABAergic neurons and pyramidal cells. FS-GABA neurons were identified on the basis of their morphology and electrophysiological properties (Kawaguchi and Kubota, 1997; Markram et al., 2004). To record unitary IPSCs (uIPSCs) in star pyramidal and pyramidal cells, presynaptic fast-spiking cells were held in the current-clamp mode and their firing properties were assessed by delivering $500 \mathrm{~ms}$ depolarizing current steps. The internal solution for current- 


\section{A Layer 4}

\section{Amplitude of IPSC}

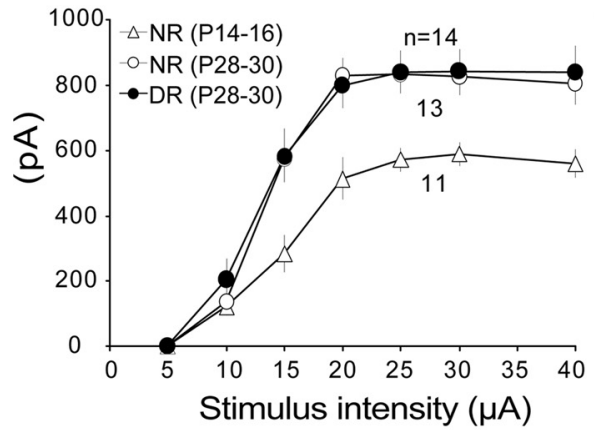

\section{IPSC/EPSC}

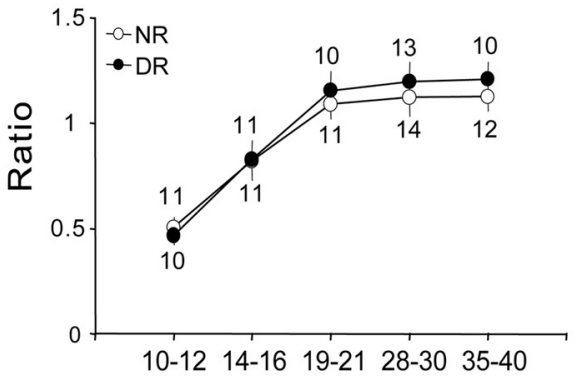

3. Amplitude of isolated IPSC

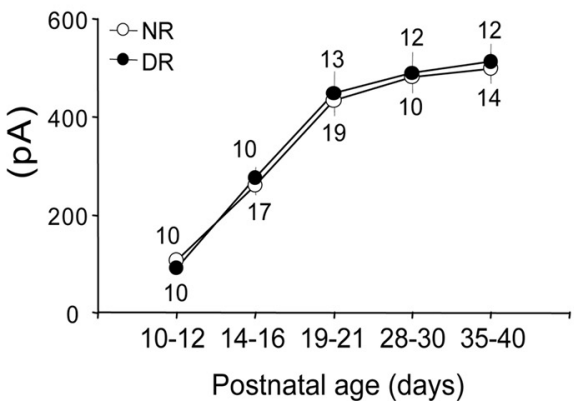

B Layer $2 / 3$
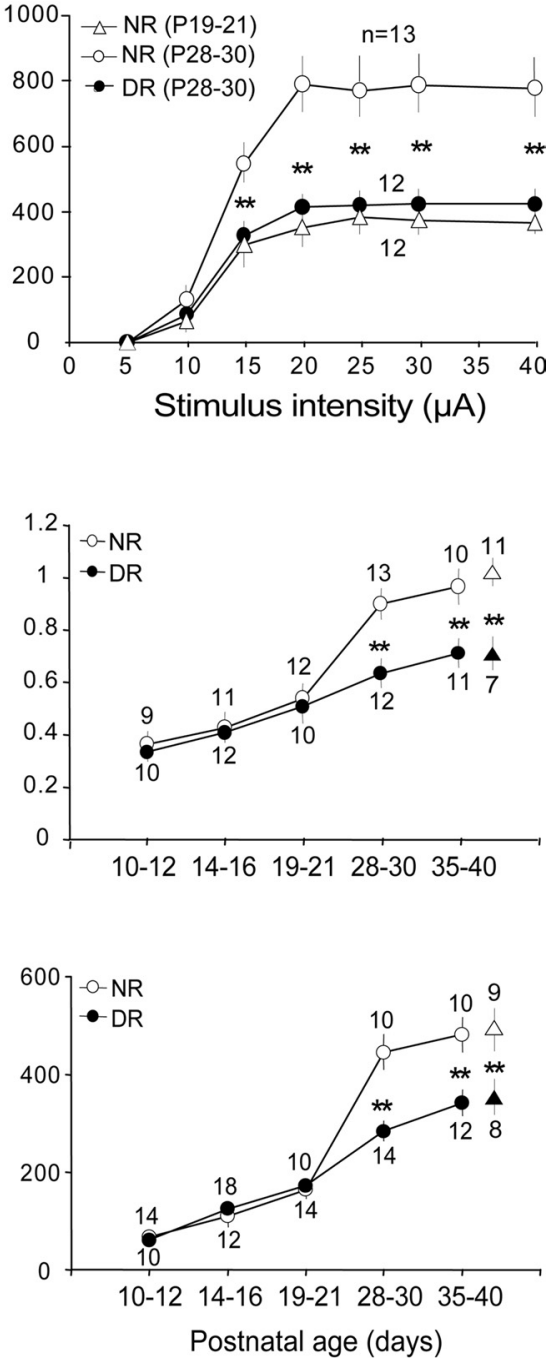

Figure 2. Effects of age and visual deprivation on functional development of GABAergic transmission. $A, B$, Data obtained from layers $4(\boldsymbol{A})$ and $2 / 3(\boldsymbol{B}) . \boldsymbol{A} \mathbf{1}, \boldsymbol{B} \mathbf{1}$, Input- output relationship of the amplitude of elPSCs recorded in layer $4(\boldsymbol{A} \boldsymbol{1})$ and layer $2 / 3(\boldsymbol{B} 1)$. Open triangles and circles indicate data from NR mice of the indicated age group. Filled circles indicate data from dark-reared animals. Each point is the mean value obtained from the number of cells indicated (above the points for NR and below the points for DR). A2, B2, Developmental changes in the //E ratio in layer 4 (A2) and layer 2/3 (B2). Open and filled circles indicate data from normally reared and dark-reared mice, respectively. $A 3, B 3$, Developmental changes in the maximal amplitude of the pharmacologically isolated IPSCs recorded in the presence of APV and CNQX in layer 4 ( $A 3$ ) and layer 2/3 (B3). Other conventions are the same as in $\mathbf{2}$. In $\mathbf{B}$ and $\mathbf{B}$, filled and open triangles indicate data from dark-reared and light-exposed mice, respectively. ${ }^{*} p<0.01$.

clamp recordings contained the following (in mM): $130 \mathrm{~K}$-gluconate, 10 $\mathrm{KCl}, 10$ HEPES, $0.5 \mathrm{Na}_{3} \mathrm{GTP}, 4 \mathrm{MgATP}, 10 \mathrm{Na}$-phosphocreatine, and $0.2 \%$ biocytin, $\mathrm{pH} 7.2-7.4$. The osmolarity was $275-290 \mathrm{mOsm}$. Once an FS-GABA neuron was identified on the basis of its firing pattern, an appropriate current (usually $<500 \mathrm{pA}$ for $5 \mathrm{~ms}$ ) was injected to evoke one action potential.

To measure the effects of frequency-dependent depression of uIPSCs during repetitive presynaptic firings, trains of 10 presynaptic action potentials were elicited at $30 \mathrm{~Hz}$. Postsynaptic pyramidal cell recording was performed in the voltage-clamp mode to record uIPSCs at $-60 \mathrm{mV}$. To observe IPSCs as inward currents, an intracellular pipette contained the following solution (in $\mathrm{mm}$ ): $130 \mathrm{CsCl}, 8 \mathrm{NaCl}, 2$ EGTA, 10 HEPES, 5 QX-314, 4 ATP, 10 Na-phosphocreatine, 0.5 GTP, and 0.2\% biocytin, $\mathrm{pH} 7.4$, at 270-290 mOsm. Cells were not used for analysis if the resting membrane potential was more positive than $-55 \mathrm{mV}$, series resistance was $>25 \mathrm{M} \Omega$ or the input resistance was $<100$ $\mathrm{M} \Omega$, or if any of these parameters changed by $15 \%$ during data acquisition.

Drugs for cannabinoid receptors. As the selective agonist and antagonist for the CB1 receptor (CB1R), we used $R$-(+)-(2,3-dihydro-5-methyl3-[(4-morpholinyl)methyl]pyrol[1,2,3-de]-1,4benzoxazin-6-yl)(1-naphthalenyl) methanone mesylate [WIN55,212-2 (WIN); Tocris Bioscience] at $10 \mu \mathrm{M}$ and $N$-(piperidin-1-yl)-5-(4iodophenyl)-1-(2,4-dichlorophenyl)-4-methyl1H-pyrazole-3-carboxamide (AM251; Tocris Bioscience) at $10 \mu \mathrm{M}$, respectively. These drugs were applied through the perfusion medium in the interleaved manner in which control recordings were performed in non-drug-treated slices from the same animals.

Morphological identification of recorded cells. After electrophysiological recordings, slices containing biocytin-loaded neurons were processed in a manner similar to that described previously (Jiang et al., 2004) and observed with the two-photon laser-scanning microscope system (Sohya et al., 2007) for imaging the labeled neurons.

Data analysis. The maximal peak amplitudes of monosynaptic eEPSCs and eIPSCs were used to calculate the ratio of inhibition to excitation (I/E ratio) (Morales et al., 2002). In the synaptically connected pairs of an FS-GABA neuron to a pyramidal cell, the onset latency (from the peak of presynaptic action potential to the onset of IPSC), peak amplitude (from the baseline to the peak of IPSC), rise time (10$90 \%$ of the peak amplitude of IPSC), and decay time (time constant of a monoexponential decay function) of uIPSCs and the failure rate of generation of uIPSCs were determined on traces of 20-40 consecutive responses. Failures were judged as taking place when the measured value was $<1.5$ times the noise level within a 1 $\mathrm{ms}$ time window of the expected UIPSC peak in each pair. Noise was measured in a 1 to $2 \mathrm{~ms}$ time window before the IPSP onset (GonzalezBurgos et al., 2005). The detected uIPSP failures were also confirmed by visual inspection of the individual traces. To compare the size of frequency-dependent depression of uIPSC during the trains of presynaptic action potentials, the 2 nd to 10 th responses were normalized to the first response, and the last four responses were averaged and normalized to the first response to obtain the steady-state index.

Statistical analysis. Statistical significance was assessed using unpaired $t$ tests or one-way ANOVA followed by the Student-Newman-Keuls post hoc test. All the data reported in the text and figures represent the mean \pm SEM.

\section{Results}

Mice were grouped depending on different rearing conditions. One group of mice was reared in the normal light/dark cycle [normally reared (NR)], and the other group of mice was reared in complete darkness. In addition, some mice were dark reared from birth until P35-P40 and then exposed to light for $2 \mathrm{~d}$. We divided the data into five sequential age categories of equal duration: P10-P12 (before eye opening), P14-P16 (before the critical period) (Gordon and Stryker, 1996), P19-P21 (onset of the critical period), P28-P30 (peak of the critical period), and P35-P40 
(after the critical period). Data were acquired in an interleaved manner for comparisons among ages and rearing conditions.

\section{Sequential maturation of GABAergic inhibition from layer 4 to layer $2 / 3$}

As described in the Materials and Methods section, we recorded eEPSCs and eIPSCs from the same cells at the reversal potentials of $\mathrm{GABA}_{\mathrm{A}}$ receptor- and AMPA/NMDA receptor-mediated currents, respectively. The average reversal potentials for $\mathrm{GABA}_{\mathrm{A}}$ receptors and AMPA/NMDA receptors were $-39.7 \pm 0.8 \mathrm{mV}$ $(n=31)$ and $8.6 \pm 0.3 \mathrm{mV}(n=31)$, respectively, at P19-P21, and there were no significant changes in these values among different age categories and in different rearing conditions (data not shown). We then evaluated the strength of GABAergic inhibition in layers 4 and $2 / 3$ by measuring the magnitude of the maximal eIPSC at the different ages to quantify the development of the total inhibitory inputs converging to single pyramidal cells (Ling and Benardo, 1999; Morales et al., 2002). We also measured the $I / E$ ratio at the different ages to evaluate the relative functional development of inhibitory synapses to excitatory synapses. Representative results are shown in Figure 1 and summaries of the quantitative analysis of the results are shown in Figure 2. The staining of neurons with biocytin confirmed that recordings were performed from star pyramidal cells in layer 4 (Fig. 1A1) and pyramidal cells in layer $2 / 3$ (Fig. $1 B 1$ ). The amplitudes of eIPSCs and eEPSCs attained the plateau as the stimulus intensity was increased in both layers (Figs. 1, superimposed traces, $2 A 1, B 1$, open circles). The $I / E$ ratio measured at the plateau amplitude showed that the developmental increase was different between the two layers (Fig. 2A2,B2). In layer 4, the $I / E$ ratio was $0.51 \pm$ 0.05 at $\mathrm{P} 10-\mathrm{P} 12$, gradually increased to the plateau value (1.09 \pm $0.08)$ at $\mathrm{P} 19-\mathrm{P} 21$, and then remained at almost the same level (1.12 \pm 0.07 at P35-P40) (Fig. 2A2, open circles), suggesting that the strength of GABAergic inhibition in layer 4 attained the almost mature level around P19-P21. In layer 2/3, on the other hand, the $I / E$ ratio gradually increased from $0.37 \pm 0.05$ at $\mathrm{P} 10-$ $\mathrm{P} 12$ to $0.52 \pm 0.06$ at P19-P21, and then steeply increased to the plateau level $(0.91 \pm 0.06)$ at P28-P30 (Fig. 2 B2, open circles). These results suggest that the maturation of GABAergic transmission in layer 4 may precede that of layer $2 / 3$ by 1 week.

To observe developmental changes in eIPSCs without a possible contamination with polysynaptically evoked IPSCs, we measured the maximal amplitude of pharmacologically isolated IPSCs, which were recorded in the presence of $20 \mu \mathrm{M}$ CNQX and $100 \mu \mathrm{M}$ APV to block AMPA and NMDA receptors, respectively. Again we found that there was a difference in the developmental time course of the GABAergic synaptic potency between the two layers (Fig. 2A3,B3). In layer 4, the isolated IPSCs nearly attained the plateau $(433.6 \pm 25.1 \mathrm{pA})$ at P19-P21 (Fig. 2A3, open circles), whereas in layer $2 / 3$ such a plateau of the increase in the amplitude of isolated IPSCs was seen at P28-P30 (445.2 \pm 25.6 pA) (Fig. 2 B3, open circles). These results excluded the possibility that the arrangement of polysynaptic connections changed with age and confirmed the conclusion that the magnitude of monosynaptically evoked IPSCs increased with age.

Changes in the maximal IPSCs recorded from pyramidal cells may result from the number of inhibitory synaptic contacts, number of release sites at each contact, magnitude of the quantal response, release probability, capacity of $\mathrm{GABA}_{\mathrm{A}}$ receptors, and other factors. To clarify which of these factors is mainly involved in the developmental changes of IPSCs, we adopted paired-cell recording techniques to measure the strength and dynamics of monosynaptic connections from FS-GABAergic neurons to py-

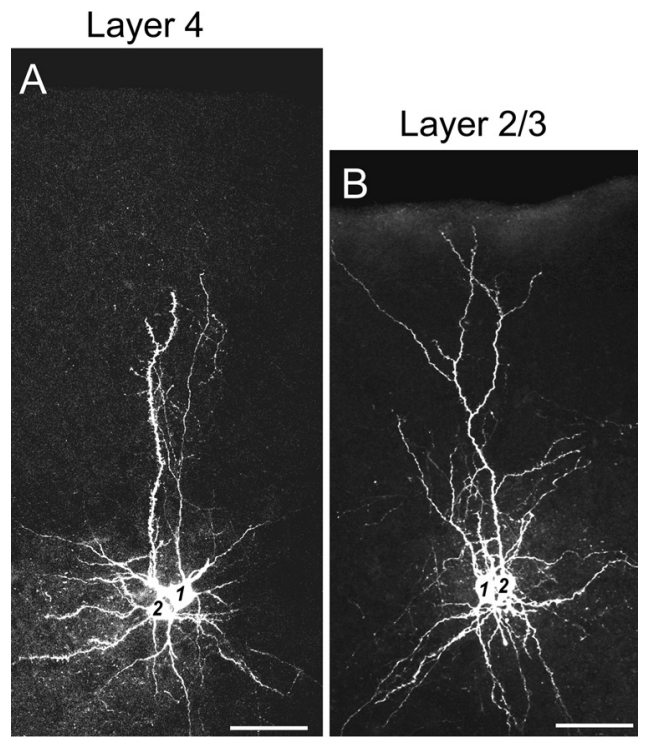

Figure 3. $\quad \boldsymbol{A}, \boldsymbol{B}$, Images of a pair of neurons that were obtained from dual-cell patch-clamp recordings in layer $4(\boldsymbol{A})$ and layer $2 / 3(\boldsymbol{B})$ of the mouse visual cortex. Cells 1 and 2 in $\boldsymbol{A}$ are a synaptically connected pair of a FS-GABA neuron and a star pyramidal neuron, respectively, in layer 4. Cells 1 and 2 in $\boldsymbol{B}$ are a synaptically connected pair of a FS-GABA neuron and a pyramidal neuron, respectively, in layer 2/3. Scale bars: $50 \mu \mathrm{m}$.

ramidal cells. To facilitate the identification of GABAergic neurons in the paired recording, we used VGAT-Venus transgenic mice. In the visual cortex, to date, several classes of GABAergic neurons are known, each of which is suggested to play a distinct functional role (Kawaguchi and Kubota, 1997; Markram et al., 2004). Of these, FS-GABA neurons that mostly contain parvalbumin (PV) are suggested to be involved in the initiation of the critical period of ocular dominance plasticity (Fagiolini et al., 2004). In the present study, therefore, we focused on the inhibitory connection from FS-GABA neurons to pyramid cells. Examples of biocytin-stained images of synaptically connected pairs of an FS-GABA neuron and a star pyramid cell in layer 4 and of another FS-GABA neuron and a pyramidal cell in layer $2 / 3$ are shown in Figure 3, $A$ and $B$, respectively. As seen in these images, synaptically connected FS-GABA neurons and pyramidal cells were usually located close together. The distance between the two somata of the cell pair in layer 4 was $\sim 15 \mu \mathrm{m}$ (Fig. $3 A$ ), and that of the cell pair in layer $2 / 3$ was $\sim 10 \mu \mathrm{m}$ (Fig. $3 B$ ). In both pairs of cells, most of the dendrites seemed to be entangled with each other. In all of the recorded pairs (139 pairs) (see Figs. 5, 7, 8 ), the distance between somata of the partners was $<50 \mu \mathrm{m}$ in both layer 4 and layer $2 / 3$. The mean distances between the somata of synaptically connected pairs of neurons were $29.4 \pm 4.1$ $\mu \mathrm{m}(n=20)$ in layer 4 and $34.2 \pm 5.6 \mu \mathrm{m}(n=20)$ in layer $2 / 3$ at P19-P21. The difference between these two values was statistically insignificant ( $t$ test, $p>0.1$ ). Thus, there was no significant difference in the soma-to-soma distance between layer 4 and layer $2 / 3$ of the visual cortex.

Then we recorded uIPSCs, which were elicited in pyramidal cells in response to action potentials of FS-GABA neurons. Examples of such records are shown in Figure 4. The relatively long latency, slow rising time, and low amplitude of uIPSCs at P12 in layers 4 and $2 / 3$ (Fig. $4 A 1, B 1$, top traces) suggest that connections from FS-GABA neurons to pyramidal cells have weak synaptic capacity in both layers at this stage of postnatal development. With development, the inhibitory transmission from FS-GABA neurons to pyramidal cells became reliable with shorter latency, 


\section{A Layer 4}

A-1
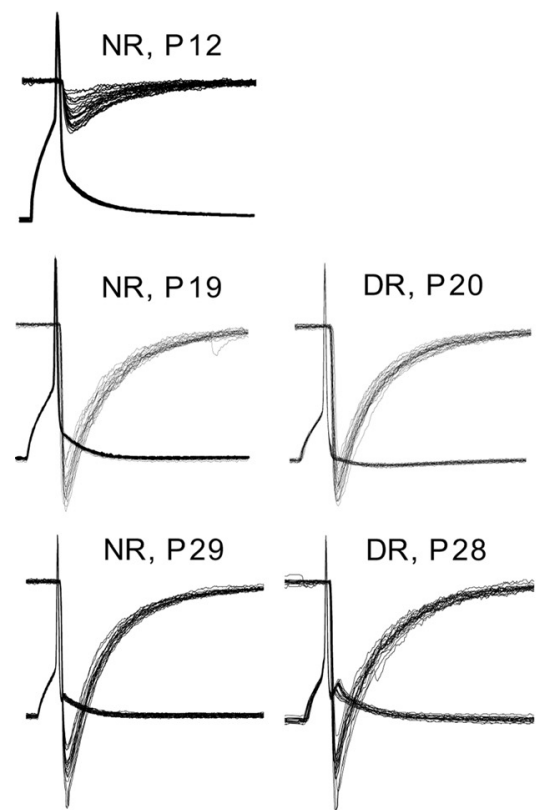

A-2

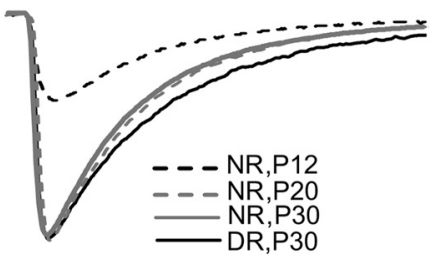

Figure 4. Representative traces of uIPSCS at different ages and in the different rearing conditions. A1, B1, Examples of ulPSC evoked in a star pyramidal neuron in layer $4(\boldsymbol{A} 1)$ and in a pyramidal neuron in layer $2 / 3(\boldsymbol{B} 1)$ by single action potentials of presynaptic FS-GABA neurons. $\mathbf{A 2}$, B2, Changes in the kinetics of uIPSCs in layer 4 and layer 2/3, respectively, at the indicated ages and in the indicated condition.

faster rise time, faster decay time, and higher amplitude. In the developmental time course of these properties of uIPSCs, there were laminar differences. In layer 4 , uIPSCs became almost mature at P19-P21 (282.3 \pm 32.5 pA) (Figs. 4A1,A2, 5A4), whereas in layer $2 / 3$ they remained still immature at P19-P21 (104.2 \pm 21.8 pA) (Figs. $4 B 1, B 2,5 B 4)$. In this layer, uIPSCs became mature finally at P28-P30 (227.4 $\pm 28.8 \mathrm{pA})$. This value was about half of the maximal amplitudes of pharmacologically isolated eIPSCs in layer 2/3 at P28-P30 (445.2 $\pm 25.6 \mathrm{pA})$. Moreover, the nearly mature amplitudes of uIPSCs in layer 4 at P19-P21 $(282.3 \pm 32.5 \mathrm{pA})$ were about half the maximal amplitudes of pharmacologically isolated eIPSCs in layer 4 at this age (433.6 \pm $25.1 \mathrm{pA}$ ). These results suggest that each of the star pyramidal cells in layer 4 and pyramidal cells in layer $2 / 3$ is innervated by at least two GABAergic neurons in the mature circuits.

The group data for the developmental changes in the onset latency, rise time, decay time, and peak amplitude of uIPSCs recorded from all of the normally reared mice are summarized in Figure 5 (open circles). It is clear that the maturation of these properties of uIPSCs took place at approximately P19-P21 in layer 4 and at P28-P30 in layer 2/3 of the visual cortex.

The overall effectiveness of synaptic inhibition also depends on the capacity of GABAergic transmission to sustain repetitive activation. To determine the effects of repetitive presynaptic firing on the functional properties of uIPSCs, trains of 10 suprathreshold currents were applied to the presynaptic FS-GABA neurons at $30 \mathrm{~Hz}$. As illustrated in Figure 6, $A$ and $B$, the amplitude of uIPSCs decreased during repetitive stimulation and reached a steady state, which depends on multiple factors, including the stimulation frequency, release probability, and rate of recovery from depression. Strong depressions of the amplitude of uIPSPs were observed during trains of stimulation at $\mathrm{P} 15$ in layer 4 and at P19 in layer 2/3 (Fig. $6 A, B$, green traces). At P28-P30, however, the frequency depression of UIPSCs was not so strong in both layers (Figs. 6A,B, red traces, $7 A 1, B 1)$. The steady-state index increased with age, from $0.39 \pm 0.03$ at $\mathrm{P} 10-\mathrm{P} 12$ to $0.53 \pm 0.01$ at P19-P21 in layer 4 , whereas it was still $0.36 \pm 0.01$ at P19-P21 and then increased to $0.53 \pm$ 0.02 at P28-P30 in layer 2/3 (Fig. 7A2,B2, open columns).

Then, we analyzed the mean failure rate induced by the action potentials of presynaptic FS-GABA neurons at the frequency of $0.067 \mathrm{~Hz}$. The mean failure rates were $0.5 \pm$ $0.4 \%$ in layer 4 at $\mathrm{P} 19-\mathrm{P} 21$ and $0.8 \pm 0.6 \%$ in layer 2/3 at P28-P30 (Fig. 7A3,B3, open columns for NR). The failure of transmission was more commonly observed in the 10th responses compared with the first responses during the repetitive stimulation of presynaptic FS-GABA neurons, and this difference was more obvious at P10-P12 than at P28-P30 (Fig. 7A3,B3, open vs hatched columns for NR).

We then analyzed the changes in the coefficient of variation (CV) of the UIPSC amplitude between the 1st and 10th responses to examine whether the decrease in amplitude is attributable to the change in the release probability of transmitters from presynaptic terminals of FS-GABA neurons. By assuming a binomial model of release (Faber and Korn, 1991; Sjöström et al., 2003), the theory predicts that if the change takes place at presynaptic sites, the changes in $\mathrm{CV}^{2}$ should be equal to or greater than the changes in the mean amplitude of uIPSCs. As shown in Figure 7, $A 4$ and $B 4$, the data points in a plot of the normalized $\mathrm{CV}^{-2}$ versus normalized changes in the mean amplitude were located on or below the diagonal line at any age category. These results confirm that the reduction in the 10th response is attributable to a change in the release probability from presynaptic sites.

The results that the frequency depression was strong in younger mice suggested that there is a higher release probability of GABA from presynaptic terminals in the younger mice, because synapses with higher release probability are expected to show strong frequency depression, which results in a smaller steady-state index (Oleskevich et al., 2000; Brenowitz and Trussell, 2001). On the other hand, the mean amplitude of uIPSCs was enhanced with age. Hence, the magnitude of uIPSCs and the probability of release are changed with development in the opposite direction. Together, these results suggest that the maturation of GABAergic synaptic transmission is accompanied by a mixture of the increase in the magnitude of unitary IPSCs, upgrade of the efficiency of postsynaptic $\mathrm{GABA}_{\mathrm{A}}$ receptors, and reduction in the presynaptic release probability. 
Difference in effects of dark rearing on inhibitory circuits between layers 4 and $2 / 3$

Visual deprivation was reported to attenuate the maturation of perisomatic GABAergic innervation in extragranular layers of the mouse visual cortex (Morales et al., 2002; Chattopadhyaya et al., 2004). To examine whether visual deprivation also retards the functional maturation of GABAergic inhibitory circuit in layer 4 in a similar manner, the five groups of mice were deprived of visual input by prolonged DR from birth to P10-P12, P14-P16, P19-P21, P28-P30, and P35-P40. In layer 4, DR in any of the different durations failed to affect the developmental change in the amplitude of maximal eIPSC. Examples of eIPSCs evoked by stimulation at the different intensities, obtained at P21 and P30, are shown in Figure $1 A$ (right column), and the mean inputoutput relationship of eIPSCs at P28-P30 is shown in Figure $2 A 1$ (filled circles). There was no significant difference in the maximal eIPSCs between dark-reared and NR mice (one-way ANOVA, $p>0.5$ ). Moreover, the $I / E$ ratio (Fig. 2A2) and amplitude of pharmacologically isolated IPSCs (Fig. 2A3) at any age were not affected by DR, compared with the age-matched control mice.

In layer $2 / 3$, on the other hand, DR from birth to P21 did not affect the maximal amplitude of eIPSCs, whereas DR to P30 reduced that of eIPSCs (Fig. $1 \mathrm{~B}$, right column). The input-output relationship of eIPSCs in DR to P28-P30 was significantly (one-way ANOVA, $p<0.01$ ) different from that of the age-matched NR mice (Fig. 2 B1, filled circles). In this layer, DR did not affect the $I / E$ ratio until P19P21 (Fig. 2 B2, filled circles). Thereafter, however, DR attenuated the developmental increase in the $I / E$ ratio (at $\mathrm{P} 28-\mathrm{P} 30$, $\mathrm{DR}, 0.57 \pm 0.05 ; \mathrm{NR}, 0.9 \pm 0.06$; $t$ test, $p<$ 0.01). Also, the maximal amplitudes of pharmacologically isolated IPSCs in layer $2 / 3$ of dark-reared mice were not significantly different until P19-P21, but thereafter became significantly lower than those of the age-matched NR mice. At P28-P30, the mean amplitude of isolated IPSCs was $284.3 \pm 21 \mathrm{pA}$, which was significantly smaller than that $(445.2 \pm 26 \mathrm{pA})$ in NR mice (Fig. $2 B 3$, filled circles) ( $t$ test, $p<0.01$ ).

In summary, these results indicated that DR barely affected the $I / E$ ratio and amplitude of monosynaptically evoked IPSCs in layer 4, whereas it affected the maturation of GABAergic transmission strength in layer $2 / 3$. The present results further suggest that visual experience is required for the functional maturation of GABAergic transmission in layer $2 / 3$ in a restricted, specific postnatal time window, because in this layer the $I / E$ ratio and amplitude of EPSCs were affected only when DR was maintained until P28-P30. Therefore, visual experience may not be essential for and $B 4$ apply to all graphs.
A Layer 4

B Layer $2 / 3$
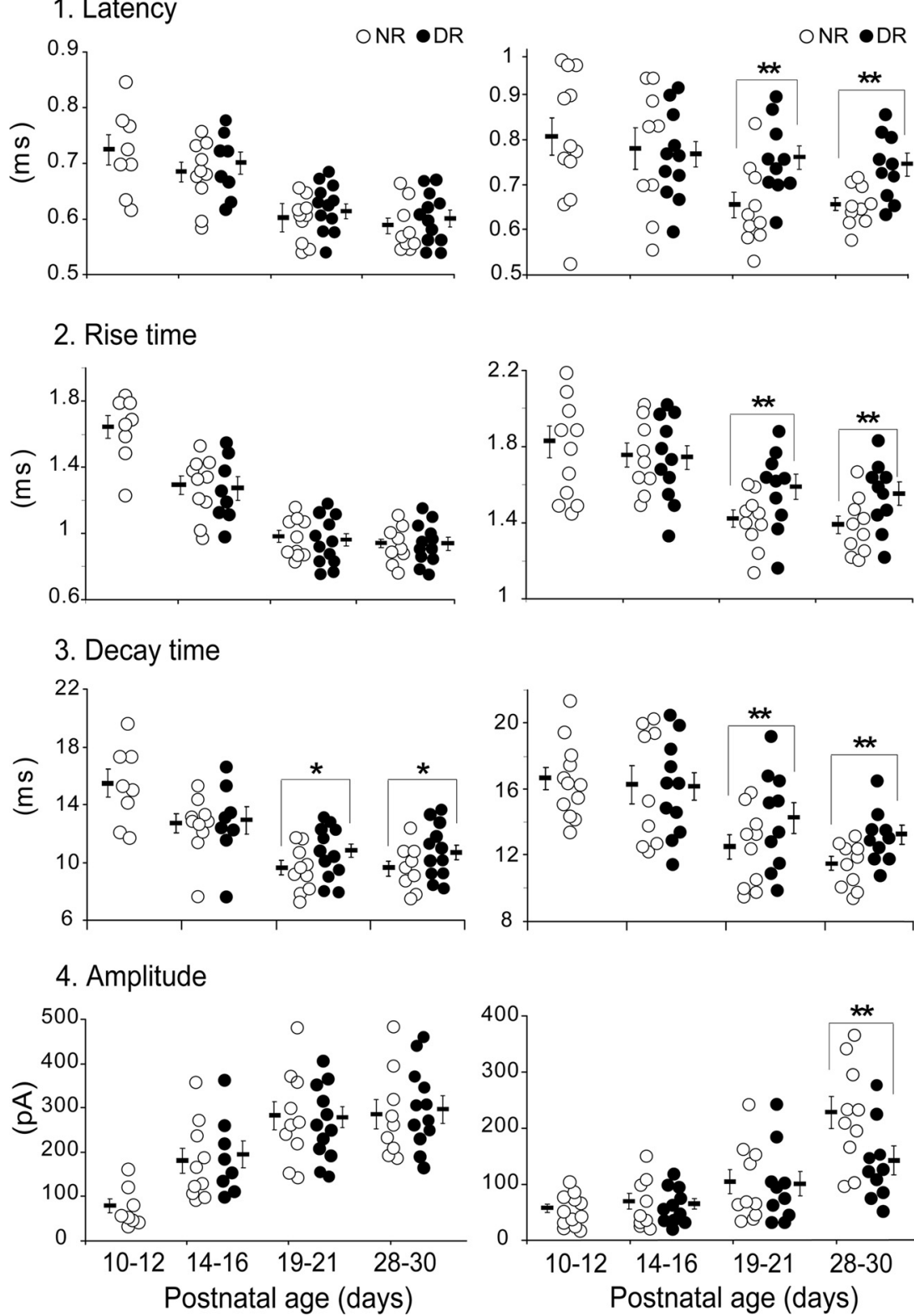

Figure 5. Effects of age and visual deprivation on strength and dynamics of ulPSCs of principal cells evoked by action potentials of FS-GABA neurons. $\mathbf{A 1}, \mathbf{B} 1$, Latency of uIPSC s of each of the star pyramidal cells in layer $4(\boldsymbol{A} 1)$ and pyramidal cells in layer $2 / 3(\boldsymbol{B} 1)$ in the age group indicated at the bottom of each column. Open and filled circles indicate values of each cell recorded from normally reared and dark-reared mice, respectively. Short horizontal and thin vertical bars indicate the mean and SEM of each age group. ${ }^{*} p<0.05$; ${ }^{* *} p<$ 0.01. $A 2, B 2$, Rise time of uIPSCs of each cell in layer $4(\boldsymbol{A 2})$ and layer $2 / 3(\boldsymbol{B} 2) . A 3, B 3$, Decay time of ulPSC s of each cell in layer $4(\boldsymbol{A 3})$ and layer 2/3 (B3). $\boldsymbol{A 4}, \boldsymbol{B} 4$, Peak amplitude of ulPSC of each cell in layer 4 ( $A 4)$ and layer $2 / 3(B 4)$. The age groups shown at the bottom of $\boldsymbol{A} 4$

the early-phase development of GABAergic inhibition in layer $2 / 3$ before $\mathrm{P} 21$.

Similar to a previous report (Morales et al., 2002), we also found that a $2 \mathrm{~d}$ light exposure (LR) reversed the effects of prolonged DR from birth to P35-P40. The I/E ratio in the LR condition was $1.01 \pm$ 0.07 (Fig. 2B2, open triangle), which was significantly ( $t$ test, $p<$ $0.01)$ larger than that $(0.66 \pm 0.06)$ in the DR condition (filled triangle). Also, the peak amplitude of pharmacologically isolated IPSCs in the LR condition ( $489 \pm 36 \mathrm{pA}$ ) was significantly ( $t$ test, $p<0.01$ ) larger than that $(349 \pm 29 \mathrm{pA})$ in the DR condition (Fig. 2 B3, open and filled triangles, respectively). 


\section{A Layer 4}

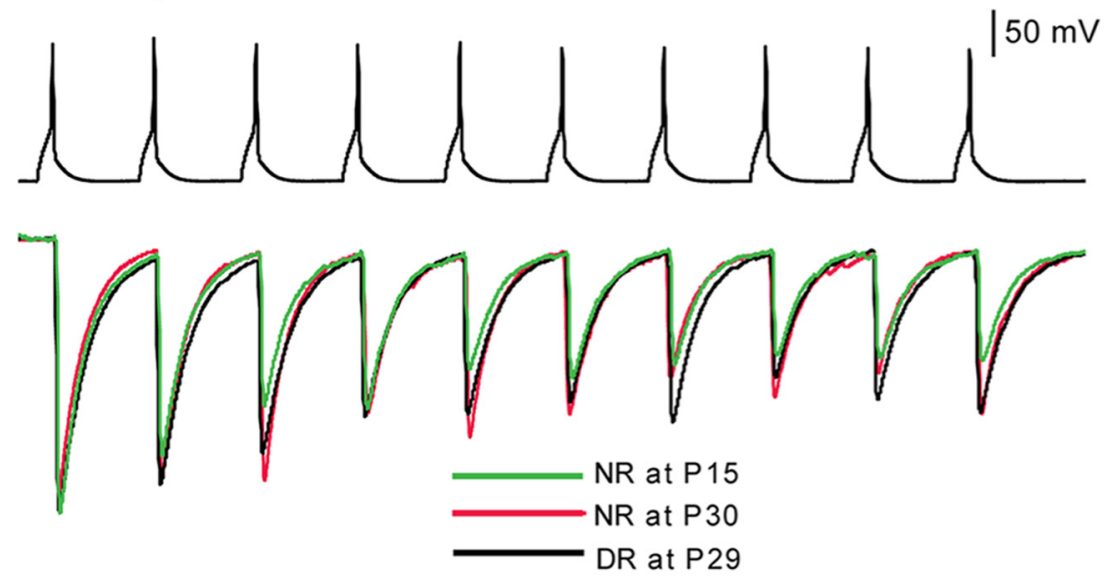

B Layer $2 / 3$

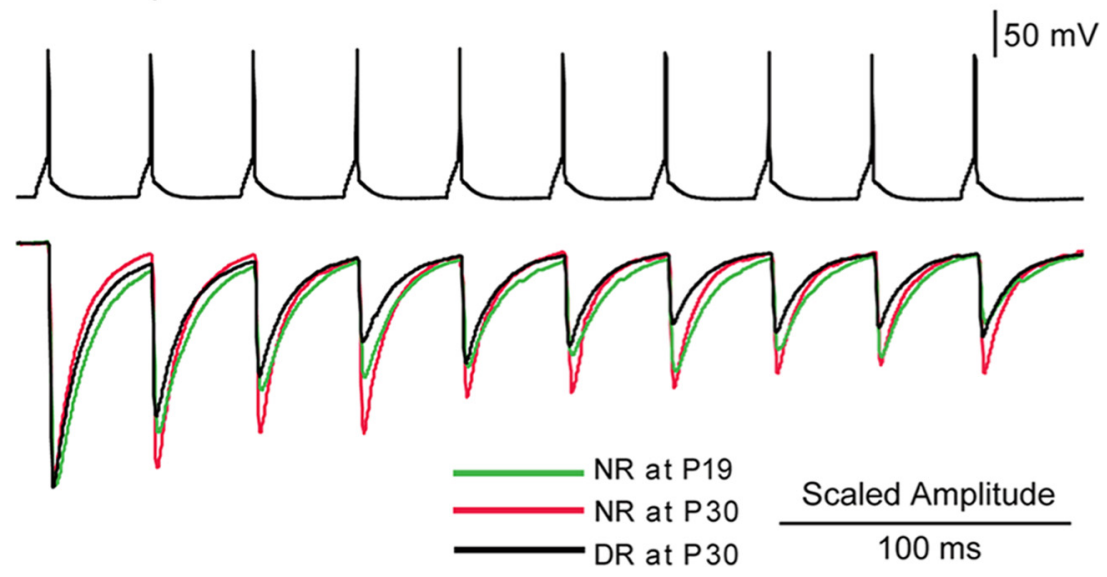

Figure 6. $\quad \boldsymbol{A}, \boldsymbol{B}$, Examples of frequency-dependent depression of uIPSCS recorded from a star pyramidal cell in layer $4(\boldsymbol{A})$ and from a pyramidal cell in layer $2 / 3(B)$ in response to sustained presynaptic firings at $30 \mathrm{~Hz}$ induced in paired FS-GABA neurons in the same layer. Ages or rearing conditions of the mice from which the records were obtained are shown in different colors, as indicated. The peak amplitudes of the uIPSCs recorded under different age and rearing conditions were scaled to the first responses for comparison.

Regarding the properties of uIPSCs, dark rearing slightly attenuated the developmental decrease in the decay time, but did not affect the developmental change in the latency, rise time, and amplitude in layer 4 (Fig. $5 A 1-A 4$, filled circles). In layer $2 / 3$, on the other hand, visual deprivation until P19-P21 impaired the developmental decline of latency, rise time, and decay time of uIPSCs, and visual deprivation until P28-P30 reduced the amplitude of uIPSCs as well (Figs. $4 B 2,5 B 1-B 4$, filled circles). As shown in blue and red traces in Figure $6 A$, four weeks of prolonged DR from birth did not attenuate the developmental increase in the steady-state index of frequency-dependent depression in layer 4 . The mean index at P28-P30 for DR (0.55 土 0.03 ) was not significantly ( $t$ test, $p>0.5$ ) different from that for normal rearing $(0.53 \pm 0.03)$ (Fig. $7 A 1, A 2$, two rightmost columns). In layer $2 / 3$, on the other hand, DR strongly delayed the developmental increase in the steady-state index. This is seen in exemplified records of frequency-dependent depression of IPSCs in layer $2 / 3$ (Fig. $6 B$, red and blue traces). The mean steady-state index for DR at P28-P30 $(0.39 \pm 0.01)$ was significantly $(t$ test, $p<0.01)$ smaller than that for normal rearing $(0.53 \pm 0.02)$ (Fig. $7 B 1, B 2$, rightmost two columns). As mentioned above, failures of transmission were more commonly observed in the 10th uIPSC compared with the first uIPSC during the trains at $30 \mathrm{~Hz}$ in dark-reared than that in NR mice (at P28-P30, $9.22 \pm 2.45$ vs
$2.57 \pm 1.22 ; p<0.01)$ (Fig. 7B3). Furthermore, the CV analysis of the uIPSC amplitudes in dark-reared mice at P28-P30 indicated that the frequency-dependent depression of uIPSCs was attributable to a decrease in the release probability at presynaptic sites (Fig. 7B4). This, together with the results shown in Figure 7, B1 and $B 3$, the GABA release probability in darkreared mice seemed to be higher than that in NR mice at the same age. Therefore, the GABAergic inhibitory circuitry in layer $2 / 3$ remained at an immature state until the appropriate visual experience was provided. Thus, $2 \mathrm{~d}$ light exposure reversed the DR effects.

To exclude the possibility that dark rearing may significantly affect the membrane properties, such as the input resistance and membrane capacitance of visual cortical neurons in both layers 4 and 2/3, we measured the developmental changes in membrane resistance and capacitance at different ages and in different rearing conditions (Fig. 8A1,A2,B1,B2). We also normalized the amplitude of uIPSC by membrane capacitance for each cell as shown in Figure 8, A3 and B3. Membrane resistance and capacitance showed opposite changes with age in both layers (Fig. 8, compare $A 1$ with $A 2, B 1$ with $B 2$ ), suggesting that both star pyramidal and pyramidal cells in layers 4 and $2 / 3$ became bigger during postnatal development. Dark rearing did not affect the development of the size of principal cells in both layers no matter how long the animals suffered from the visual deprivation (Fig. $8 A 1, A 2, B 1, B 2$, filled circles). Regarding the normalized uIPSC for each cell in layer $2 / 3$, the mean values at P28-P30 for DR $(1.2 \pm 0.3)$ were significantly $(t$ test, $p<0.01)$ smaller than those of NR peers $(1.8 \pm 0.3)$ (Fig. $8 B 3$ ), suggesting that the decrease in the amplitude of IPSCs did not result from a decrease in cell size in layer $2 / 3$. In layer 4 , however, the uIPSCs normalized by membrane capacitance for each cell were not affected by visual deprivation (at P28-P30, DR, $2.8 \pm 0.3$; NR, $2.68 \pm 0.3 ; t$ test, $p>0.5$ ) (Fig. 8 A3).

Collectively, the results indicate that DR affects the GABAergic transmission in layer $2 / 3$, resulting from an increase in the failure of synaptic transmission, a decrease in the amplitude of unitary IPSCs, and increases in release probability and decay time of uIPSCs. In layer 4, however, DR affects the development of inhibitory circuit differently by slightly prolonging the decay time of uIPSCs. These results suggest that visual experience mediates the strength of GABAergic inhibition on principal cells in layers $2 / 3$ and 4 in a different manner.

\section{Difference in action of endocannabinoids between layers $2 / 3$ and 4}

Because endocannabinoid-dependent LTD of GABAergic synaptic transmission has been found necessary for the maturation process of inhibitory synapses in layer $2 / 3$ of the rodent visual cortex (Jiang et al., 2010), the laminar difference in maturation of GABAergic syn- 
apses may be related to a difference in functional effectiveness of cannabinoid receptors. To test this possibility we applied WIN, an agonist for CB1R, to cortical slices. As reported previously (Jiang et al., 2010), WIN depressed eIPSCs recorded from layer 2/3 pyramidal cells at P14-P16 (Fig. $9 A 1, A 2)$. The increase in the paired-pulse ratio of eIPSCs during the WIN-induced depression (Fig. 9A3) suggests that this depression is ascribable to a presynaptic change. In contrast to the clear change in layer $2 / 3$, WIN was not effective on eIPSCs recorded from star pyramidal cells in layer 4 in the same age group (Fig. 9A1, right, $A 2$, open circles). The action of WIN on eIPSCs of layer $2 / 3$ pyramidal cells was blocked by the prior application of the antagonist for CB1R (Fig. 9B1). Also, the depressive action of WIN in layer 2/3 was not seen in CB1-KO mice (Fig. $9 B 2$, open circles). These results indicate that the depressive action of WIN in layer $2 / 3$ is mediated by $\mathrm{CB} 1 \mathrm{R}$, as reported previously in the rodent visual cortex (Jiang et al., 2010).

The depressive action of WIN on eIPSCs in layer 2/3 was seen at P10-P12, P14-P16, and P19-P21, but not seen at P28-P30 (Fig. $9 C$, filled circles). In CB1-KO mice, WIN was not effective in layer $2 / 3$ even at P14P16 (filled triangle). In layer 4, on the other hand, eIPSCs were not sensitive to WIN at any ages tested (Fig. 9C, open circles). These results suggest that endocannabinoids are not involved in the maturation of GABAergic inhibition in layer 4 of the visual cortex, whereas they may play a role in the developmental maturation of GABAergic inhibition in layer $2 / 3$. To confirm this suggestion, we analyzed the input-output relationship of eIPSCs in the two layers of CB1-KO mice at P28-P30 when GABAergic synapses in normally reared, wild-type mice are already matured (Figs. 2, 5). The eIPSCs are thought to be induced by GABA released from the two types of presynaptic terminals, axon terminals of FS and non-FS interneurons (Jiang et al., 2010). To exclusively record the component of eIPSCs that was elicited through axons of FS interneurons, a blocker for N-type voltage-dependent $\mathrm{Ca}^{2+}$ channels, Ctx, was applied to slices at $300 \mathrm{~nm}$, because this type of $\mathrm{Ca}^{2+}$ channel is known to mediate GABA release from non-FS interneurons, and thus Ctx does not affect GABA release from FS interneurons (Wilson et al., 2001; Zaitsev et al., 2007). In layer $2 / 3$ of the $\mathrm{KO}$ mice, the input-output relationship of eIPSCs recorded in this way was significantly different from that in wild-type mice at P28-P30 when eIPSCs were matured (Fig. 9D, left). In layer 4, on the other hand, no significant difference was seen between CB1-KO and wild-type mice (Fig. 9D, right). These results suggest that endocannabinoids may participate at least partly in the maturation of
B Layer 2/3

\section{Relative amplitude}
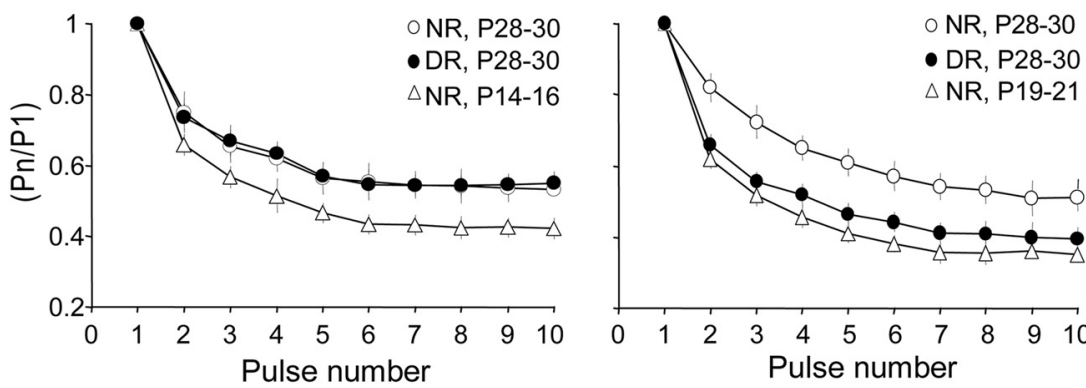

\section{Steady state}
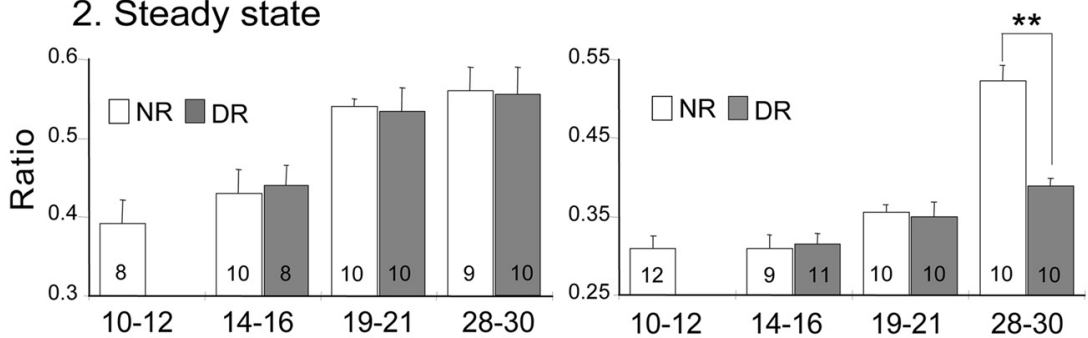

3. Failure rate
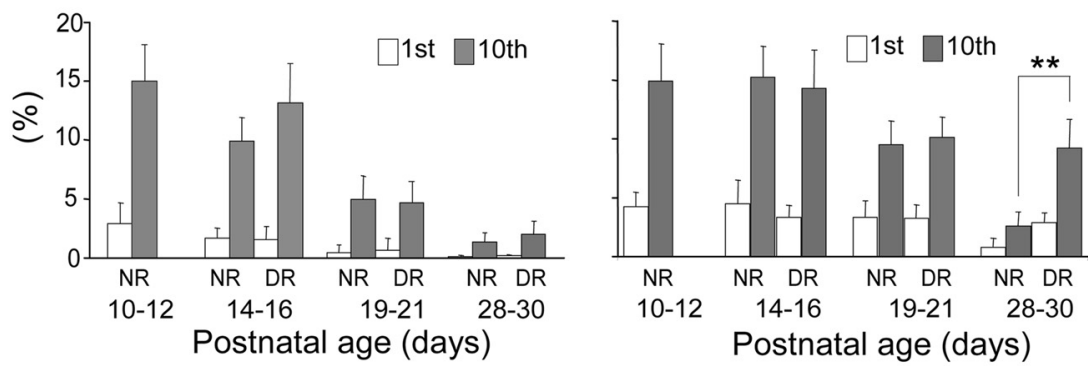

\section{4. $\mathrm{CV}^{-2}$ vs Amplitude}
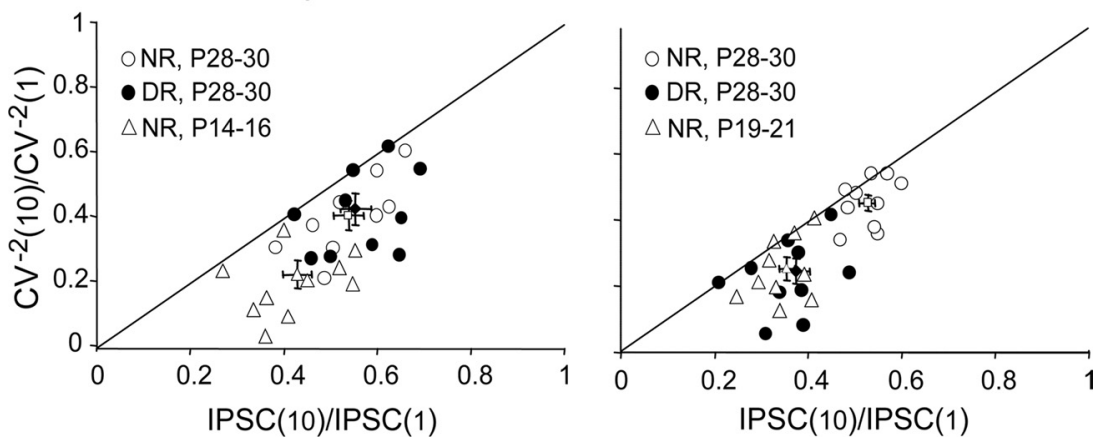

Figure 7. $A, B$, Effects of age and visual deprivation on the parameters reflecting changes in presynaptic components of GABAergic transmission. $\boldsymbol{A 1}$, B1, Changes in the frequency-dependent depression of uIPSC amplitude in layer $4(\boldsymbol{A} 1)$ and layer $2 / 3(B 1)$. A2, B2, Changes in steady-state index in layer 4 ( $A 2)$ and layer 2/3 (B2). The numbers in each column indicate the number of pairs of dual whole-cell recordings. $\boldsymbol{A} 3, \boldsymbol{B} 3$, Changes in failure rate in layer $4(\boldsymbol{A} 3)$ and layer $2 / 3(B 3) . A 4, B 4$, Relationship between changes in CV of the IPSC amplitudes and changes in mean amplitude in layer 4 (A4) and layer 2/3 (B4). Short vertical and horizontal bars indicate the mean \pm SEM for the normalized value of $\mathrm{CV}^{-2}$ and for the normalized mean value for each group indicated, respectively. ${ }^{* *} p<0.01$.

GABAergic synapses from FS interneurons to pyramidal cells in layer $2 / 3$ of the visual cortex.

\section{Discussion}

Sequential development of GABAergic synaptic function from layers 4 to $2 / 3$

The present results have demonstrated that the maturation of IPSCs evoked by afferent stimulation or by action potentials of simultaneously recorded FS-GABA neurons in layer 4 of the 
A Layer 4

\section{Membrane resistance}

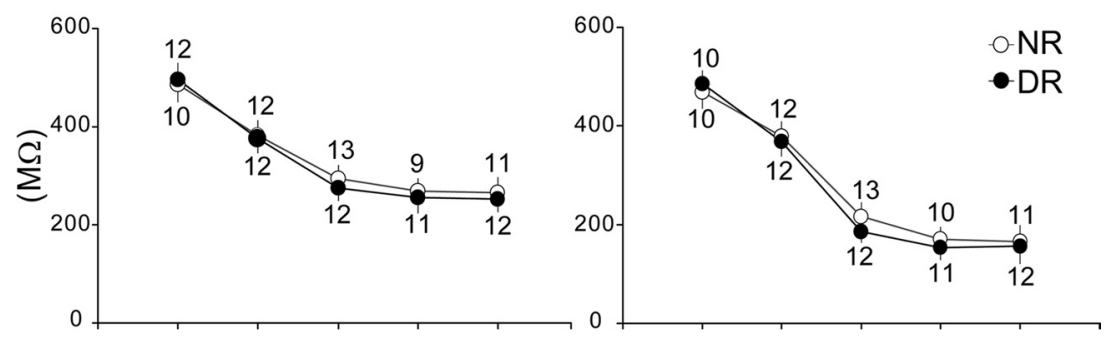

\section{Membrane capacitance}
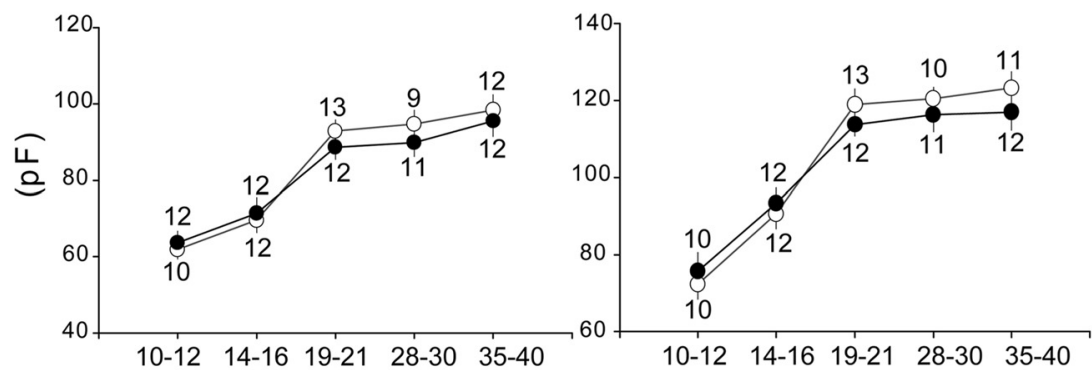

3. uIPSC/ Cm
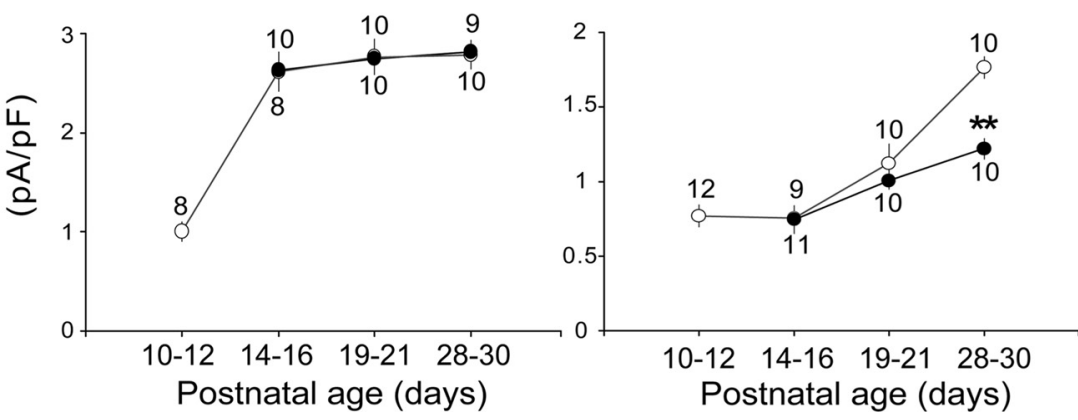

Figure 8. $\quad \boldsymbol{A}, \boldsymbol{B}$, Visual deprivation does not affect the passive properties of star pyramidal cells in layer 4 and pyramidal cells in layer $2 / 3 . A 1, B 1$, Changes in membrane resistance in layer $4(\boldsymbol{A} 1)$ and layer $2 / 3(\boldsymbol{B} 1) . \boldsymbol{A 2}, \mathbf{B 2}$, Changes in membrane capacitance in layer 4 (A2) and layer 2/3 (B2). A3, B3, Changes in the peak amplitude of ulPSCs divided by membrane capacitance in layer 4 $(A 3)$ and layer $2 / 3(B 3)$. Other conventions are the same as those in Figure $2 .{ }^{* *} p<0.01$.

mouse visual cortex takes place at postnatal week 3, which precedes by 1 week that of layer $2 / 3$. Therefore, the GABAergic inhibitory circuits seem to functionally develop in a sequential manner from layers 4 to $2 / 3$ of the visual cortex. Previous studies on excitatory synapses reported that there is a sequential development of the Hebbian form of plasticity across layers in the visual cortex: LTP and LTD become uninducible in layer 4 shortly after the eyes open, whereas they remain inducible in layer $2 / 3$ even in adulthood (Dudek and Friedlander, 1996; Jiang et al., 2007). Moreover, synaptic scaling, another activity-dependent form of synaptic plasticity in the visual cortex, also exhibits an early critical period in layer 4 (Desai et al., 2002) and persists in layer 2/3 in the adult (Goel et al., 2006; Goel and Lee, 2007). Previous in vivo studies also showed that initially the neuronal plasticity is present in thalamic recipient layers, and later in superficial layers of the somatosensory and visual cortices (Fox, 1992; Pham et al., 2004; Tagawa et al., 2005). Therefore, the plasticity of excitatory synapses in the cortex attenuates in a sequential manner from layer 4 to supragranular layers of the cortex. This laminar-specific timing of the rise and fall of plasticity of excitatory synapses very well matches the time course of sequen- tial maturation of GABAergic transmission to principal cells in layers 4 and $2 / 3$.

Laminar-specific effects of dark rearing on development of GABAergic synapses The present results indicate that prolonged dark rearing exerted differential effects on the components of inhibitory synaptic inputs in different layers of the visual cortex. In layer $2 / 3$, dark rearing may not only suppress the proliferation of GABAergic terminals, but also alter the capacity of $\mathrm{GABA}_{\mathrm{A}}$ receptors. In layer 4, on the other hand, dark rearing has little effect on the presynaptic components and seems to partly circumscribe the development of function of postsynaptic $\mathrm{GABA}_{\mathrm{A}}$ receptors in the sense that the decay time of IPSC is prolonged by dark rearing.

The present results also indicate that in layer $2 / 3$, there is a specific time window (from eye opening to $\mathrm{P} 40$ ) in which visual experience is required for the normal development of strength of GABAergic transmission. These results therefore suggest that the maturation of the GABAergic circuit in layer $2 / 3$ of the primary visual cortex is regulated by experience-driven inputs only during a restricted period of postnatal development. The result that the inhibitory circuit in layer 4 is less susceptible to visual deprivation is consistent with previous observations that dark rearing does not affect the critical period for experience-dependent remodeling of thalamocortical inputs to layer 4 of the cat visual cortex (Mower et al., 1985), and that dark rearing does not have any effect on the induction of LTP/LTD in layer 4 of the mouse visual cortex (Jiang et al., 2007), although monocular lid suture for $3 \mathrm{~d}$ occluded the subsequent LTD induction in both layers $2 / 3$ and 4 of the mouse visual cortex (Crozier et al., 2007). The weaker susceptibility of the inhibitory circuit in layer 4 to visual deprivation implies that the postnatal development of perisomatic GABAergic innervation to star pyramidal cells may be regulated by activity-independent processes.

Presynaptic and postsynaptic contributions to developmental and deprivation-induced changes in GABAergic synapses Both presynaptic and postsynaptic changes could potentially contribute to the changes in the strength of GABAergic transmission during postnatal development and by dark rearing. For postsynaptic sites, the results that the rise and decay times of the uIPSCs decreased with age suggest that the functional maturation of postsynaptic $\mathrm{GABA}_{\mathrm{A}}$ receptors may take place with development (Heinen et al., 2004; Luhmann and Prince, 1991). Also, the findings that dark rearing attenuated the developmental decrease in the rise and decay times of the UIPSCs in layer $2 / 3$ suggest that dark rearing may retard the development of the function of postsynaptic $\mathrm{GABA}_{\mathrm{A}}$ receptors. This seems to be consistent with the previous reports that dark rearing results in a significant decrease in the density of GABA-immunoreactive neurons in the rat 
visual cortex (Benevento et al., 1995) and in the $\mathrm{GABA}_{\mathrm{A}}$ receptor function around the somatoproximal dendritic region of neurons in layer $2 / 3$ of the mouse visual cortex (Katagiri et al., 2007).

For presynaptic sites, the present results that the failure rate of uIPSCs decreased and the steady-state index of uIPSCs during repetitive stimulation increased with age suggest that the release probability of GABAergic synapses changes from an immature state with high release probability but prone to depletion to a mature state with the lowered release probability but increased fidelity of transmission. Dark rearing may hinder this functional maturation of GABAergic terminals, resulting in a small peak amplitude of uIPSCs with loose temporal fidelity of GABAergic synaptic transmission in layer $2 / 3$.

Also, we found that the peak amplitude of UIPSCs was enhanced with age, and dark rearing until P28-P30 attenuated this enhancement in layer $2 / 3$. The peak amplitude of uIPSCs reflects the total activities of inhibitory terminals proliferating at a postsynaptic cell from an axon of an FS-GABA neuron. Therefore, it is possible to suggest that the numbers of functionally active GABAergic contacts on pyramidal cells in layer $2 / 3$ may increase with age in an activity-dependent manner. On the basis of the comparison of the amplitudes of UIPSCs with those of pharmacologically isolated IPSCs, we propose that during postnatal development, star pyramidal cells in layer 4 and pyramidal cells in layer $2 / 3$ may obtain inhibitory innervations from at least two GABAergic neurons.

These results are consistent with previous finding that visual deprivation attenuates the total GABAergic inputs converging to pyramidal cells in layer 2/3 (Morales et al., 2002), although there were a few, possibly inconsistent, results that the immunoreactivity of GABA-synthesizing enzymes in the cat visual cortex and the expression of $\mathrm{GABA}_{\mathrm{A}}$ receptor subunits in the rat visual cortex were unchanged in the dark-rearing condition (Mower and Guo, 2001; Heinen et al., 2004).

Laminar difference in the effectiveness of activation of CB1Rs The present results demonstrate that eIPSCs of layer $2 / 3$ neurons are sensitive to the $\mathrm{CB} 1 \mathrm{R}$ agonist at $\mathrm{P} 10-\mathrm{P} 21$ and become insensitive at P28-P30, whereas those of layer 4 neurons are not sensitive at any age tested. Thus, it seems possible that endocannabinoid-involved mechanisms for maturation of GABAergic inhibitory synapses operate in layers $2 / 3$ but not in layer 4 of the visual cortex. Because the maturation of GABAergic inhibitory synapses in layer $2 / 3$ of the rat visual cortex requires endocannabinoid-mediated LTD before 4 postnatal weeks (Jiang et al., 2010), high-frequency inputs that are derived from normal visual experience may activate the endocannabinoid system so as to play a role in the functional maturation of the inhibitory system in this
B

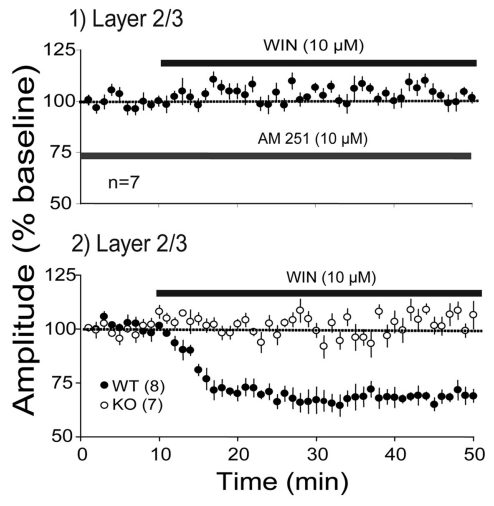

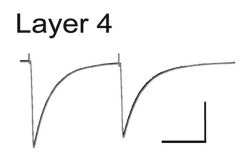

3) PPR

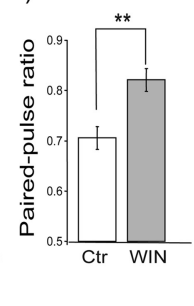

D Layer $2 / 3$

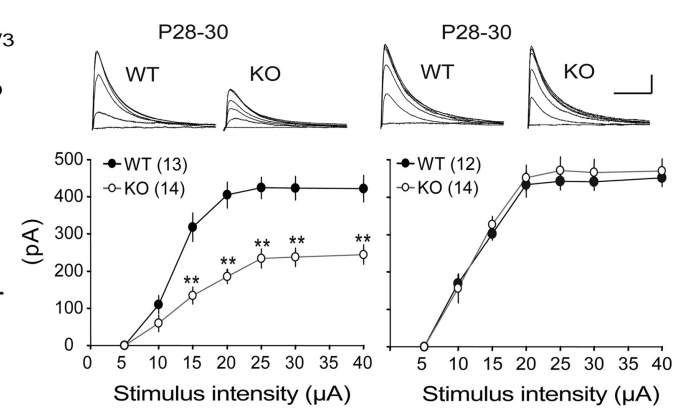

Figure 9. Laminar difference in involvement of CB1Rs in GABAergic synaptic transmission. A1, Examples of elPSCs of a layer 2/3 neuron (left) and a layer 4 neuron (right). Responses to paired-pulse stimulation before the application of WIN are superimposed with those during the application. Averages of 10 sweeps for each. Calibration: 50 ms, 100 pA. A2, Time courses of change or no Of the second responses to that of the first responses. B1 The amplitudes of eEPSC s of layer 2/3 neurons at P14 -P16 are plotted against time. AM251 and WIN were applied, as indicated. B2, The amplitudes of eEPSCs of layer 2/3 neurons of CB1-KO mice (open and wild-type mice (filled circles) at P14-P16. C, The depressive or no effects of WIN on elPSCs in layer 2/3 and layer 4 of mean amplitude of eIPSC during the WIN application to amplitude of elPSCs recorded in layer 2/3 (left) and layer 4 (right). At top, traces are superimposed as shown in Figure 1. Calibration: mice (filled circles) are plotted against the intensity of stimulation. Asterisks indicate that the difference in the value between CB1-K0 and wild-type mice is significant at $p<0.01$.

layer. On the other hand, the maturation of GABAergic synapses in layer 4 is not regulated by endocannabinoids, and thus is less effectively influenced by visual experience. This suggestion has been confirmed by the observation that the normal maturation of GABAergic synaptic function in layer 2/3 of the cortex at P28-P30 was not seen in CB1-KO mice.

In this context, it is interesting to note that LTD of excitatory synapses in layer $2 / 3$ of the mouse visual cortex was blocked by the CB1R antagonist, whereas that in layer 4 was not (Crozier et al., 2007), and ocular dominance plasticity in layer $2 / 3$ was disturbed by the antagonist, but that in layer 4 was not (Liu et al., 2008). Although these studies analyzed EPSCs or visually evoked potentials mostly reflecting excitatory responses, it seems to possible to assume that the endocannabinoid system operates both at excitatory and inhibitory synapses in layer $2 / 3$ of the visual cortex during the immature phase, whereas this system does not effectively operate at either type of synapses in layer 4 .

In autoradiographic assays using a radiolabeled synthetic cannabinoid, it was reported that the neocortex of various animals including rats showed moderate binding with peaks in superficial 
and deep layers, although radiolabeled cells were not classified as excitatory or GABAergic (Herkenham et al., 1990). In the mouse visual cortex, it was reported that immunoreactivity to CB1R was observed mainly in inhibitory nerve terminals containing vesicular GABA transporters rather than excitatory terminals containing vesicular glutamate transporters in layers $2 / 3$ and 6 , although inhibitory terminals were not further classified (Yoneda et al., 2009). In the rat hippocampus, it was reported that FS-PV neurons were immunocytochemically negative for CB1Rs (Katona et al., 1999). Within our knowledge, there were no reports on the presence or absence of CB1R immnunoreactivity in FS-PV neurons in the mouse visual cortex. As discussed previously, immunocytochemistry is not always sensitive enough to detect CB1Rs in PV-positive interneurons (Jiang et al., 2010). Taking these considerations together, it is possible to conclude that the endocannabinoid system does not effectively operate at any age in layer 4 of the mouse visual cortex, whereas it may be effective in layer $2 / 3$ in the particular period of postnatal development.

\section{References}

Benevento LA, Bakkum BW, Cohen RS (1995) Gamma-aminobutyric acid and somatostatin immunoreactivity in the visual cortex of normal and dark-reared rats. Brain Res 689:172-182.

Brenowitz S, Trussell LO (2001) Minimizing synaptic depression by control of release probability. J Neurosci 21:1857-1867.

Chattopadhyaya B, Di CG, Higashiyama H, Knott GW, Kuhlman SJ, Welker E, Huang ZJ (2004) Experience and activity-dependent maturation of perisomatic GABAergic innervation in primary visual cortex during a postnatal critical period. J Neurosci 24:9598-9611.

Crozier RA, Wang Y, Liu CH, Bear MF (2007) Deprivation-induced synaptic depression by distinct mechanisms in different layers of mouse visual cortex. Proc Natl Acad Sci U S A 104:1383-1388.

Cynader M (1983) Prolonged sensitivity to monocular deprivation in darkreared cats: effects of age and visual exposure. Brain Res 284:155-164.

Cynader M, Mitchel DE (1980) Prolonged sensitivity to monocular deprivation in dark-reared cats. J Neurophysiol 43:1026-1039.

Daw NW (1995) Visual development. New York: Plenum.

Daw NW, Fox K, Sato H, Czepita D (1992) Critical period for monocular deprivation in the cat visual cortex. J Neurophysiol 67:197-202.

Desai NS, Cudmore RH, Nelson SB, Turrigiano GG (2002) Critical periods for experience-dependent synaptic scaling in visual cortex. Nat Neurosci 5:783-789.

Dudek SM, Friedlander MJ (1996) Developmental down-regulation of LTD in cortical layer IV and its independence of modulation by inhibition. Neuron 16:1097-1106.

Faber DS, Korn H (1991) Applicability of the coefficient of variation method for analyzing synaptic plasticity. Biophys J 60:1288-1294.

Fagiolini M, Pizzorusso T, Berardi N, Domenici L, Maffei L (1994) Functional postnatal development of the rat primary visual cortex and the role of visual experience: dark rearing and monocular deprivation. Vision Res 34:709-720.

Fagiolini M, Fritschy JM, Löw K, Möhler H, Rudolph U, Hensch TK (2004) Specific $\mathrm{GABA}_{\mathrm{A}}$ circuits for visual cortical plasticity. Science 303:1681-1683.

Fox K (1992) A critical period for experience-dependent synaptic plasticity in rat barrel cortex. J Neurosci 12:1826-1838.

Goel A, Lee HK (2007) Persistence of experience-induced homeostatic synaptic plasticity through adulthood in superficial layers of mouse visual cortex. J Neurosci 27:6692-6700.

Goel A, Jiang B, Xu LW, Song L, Kirkwood A, Lee HK (2006) Cross-modal regulation of synaptic AMPA receptors in primary sensory cortices by visual experience. Nat Neurosci 9:1001-1003.

Gonzalez-Burgos G, Krimer LS, Povysheva NV, Barrionuevo G, Lewis DA (2005) Functional properties of fast spiking interneurons and their synaptic connections with pyramidal cells in primate dorsolateral prefrontal cortex. J Neurophysiol 93:942-953.

Gordon JA, Stryker MP (1996) Experience-dependent plasticity of binocular responses in the primary visual cortex of the mouse. J Neurosci 16:3274-3286.

Guire ES, Lickey ME, Gordon B (1999) Critical period for the monocular deprivation effect in rats: assessment with sweep visually evoked potentials. J Neurophysiol 81:121-128.

Heinen K, Bosman LW, Spijker S, Van Pelet J, Smit AB, Voorn P, Baker RE, Brussaard $\mathrm{AB}$ (2004) $\mathrm{GABA}_{\mathrm{A}}$ receptor maturation in relation to eye opening in the rat visual cortex. Neuroscience 124:161-171.

Hensch TK (2005) Critical period plasticity in local cortical circuits. Nat Rev Neurosci 6:877-888.

Hensch TK, Fagiolini M, Mataga N, Stryker MP, Baekkeskov S, Kash SF (1998) Local GABA circuit control of experience-dependent plasticity in developing visual cortex. Science 282:1504-1508.

Herkenham M, Lynn AB, Little MD, Johnson MR, Melvin LS, De Costa BR, Rice KC (1990) Cannabinoid receptor localization in brain. Proc Natl Acad Sci U S A 87:1932-1936.

Heynen AJ, Bear MF (2001) Long-term potentiation of thalamocortical transmission in the adult visual cortex in vivo. J Neurosci 21:9801-9813.

Jiang B, Kitamura A, Yasuda H, Sohya K, Maruyama A, Yanagawa Y, Obata K, Tsumoto $\mathrm{T}$ (2004) Brain-derived neurotrophic factor acutely depresses excitatory synaptic transmission to GABAergic neurons in visual cortical slices. Eur J Neurosci 20:709-718.

Jiang B, Huang ZJ, Morales B, Kirkwood A (2005) Maturation of GABAergic transmission and the timing of plasticity in visual cortex. Brain Res Rev 50:126-133.

Jiang B, Treviño M, Kirkwood A (2007) Sequential development of longterm potentiation and depression in different layers of the mouse visual cortex. J Neurosci 27:9648-9652.

Jiang B, Huang S, de Pasquale R, Milman D, Song L, Lee H-K, Tsumoto T, Kirkwood A (2010) The maturation of GABAergic transmission in visual cortex requires endocannabinoid-mediated LTD of inhibitory inputs during a critical period. Neuron 66:248-259.

Kameyama K, Sohya K, Ebina T, Fukuda A, Yanagawa Y, Tsumoto T (2010) Difference in binocularity and ocular dominance plasticity between GABAergic and excitatory cortical neurons. J Neurosci 30:1551-1559.

Katagiri H, Fagiolini M, Hensch TK (2007) Optimization of somatic inhibition at critical period onset in mouse visual cortex. Neuron 53:805-812.

Katona I, Sperlagh B, Sik A, Kafalvi A, Vizi ES, Mackie K, Freund TF (1999) Presynaptically located $\mathrm{CB} 1$ cannabinoid receptors regulate GABA release from axon terminals of specific hippocampal interneurons. J Neurosci 19:4544-4558.

Kawaguchi Y, Kubota Y (1997) GABAergic cell subtypes and their synaptic connections in rat frontal cortex. Cereb Cortex 7:476-486.

Kirkwood A, Lee HK, Bear MF (1995) Co-regulation of long-term potentiation and experience-dependent plasticity in visual cortex by age and experience. Nature 375:328-331.

Kishimoto Y, Kano M (2006) Endogenous cannabinoid signaling through the $\mathrm{CB}_{1}$ receptor is essential for cerebellum-dependent discrete motor learning. J Neurosci 26:8829-8837.

Ling DS, Benardo LS (1999) Restrictions on inhibitory circuits contribute to limited recruitment of fast inhibition in rat neocortical pyramidal cells. J Neurophysiol 82:1793-1807.

Liu CH, Heynen AJ, Hussain Shulter MG, Bear MF (2008) Cannabinoid receptor blockade reveals parallel plasticity mechanisms in different layers of mouse visual cortex. Neuron 58:340-345.

Luhmann HJ, Prince DA (1991) Postnatal maturation of the GABAergic system in rat neocortex. J Neurophysiol 65:247-263.

Maffei A, Nelson SB, Turrigiano GG (2004) Selective reconfiguration of layer 4 visual cortical circuitry by visual deprivation. Nat Neurosci 7:1353-1359.

Markram H, Toledo-Rodrigues M, Wang Y, Gupta A, Silberberg G, Wu C (2004) Interneurons of the neocortical inhibitory system. Nat Rev Neurosci 5:793-807.

Morales B, Choi SY, Kirkwood A (2002) Dark rearing alters the development of GABAergic transmission in visual cortex. J Neurosci 22:8084-8090.

Mower GD, Guo Y (2001) Comparison of the expression of two forms of glutamic acid decarboxylase (GAD67 and GAD65) in the visual cortex of normal and dark-reared cats. Dev Brain Res 126:65-74.

Mower GD, Caplan CJ, Christen WG, Duffy FH (1985) Dark rearing prolongs physiological but not anatomical plasticity of the cat visual cortex. J Comp Neurol 235:448-466.

Oleskevich S, Clements J, Walmsley B (2000) Release probability modulates short-term plasticity at a rat giant terminal. J Physiol 524:513-523.

Pham TA, Graham SJ, Suzuki S, Barco A, Kandel ER, Gordon B, Lickey ME (2004) A semi-persistent adult ocular dominance plasticity in visual cortex is stabilized by activated CREB. Learn Mem 11:738-747. 
Sato M, Stryker MP (2008) Distinctive features of adult ocular dominance plasticity. J Neurosci 28:10278-10286.

Sawtell NB, Frenkel MY, Philpot BD, Nakazawa K, Tonegawa S, Bear MF (2003) NMDA receptor-dependent ocular dominance plasticity in adult visual cortex. Neuron 38:977-985.

Sjöström PJ, Turrigiano GG, Nelson SB (2003) Neocortical LTD via coincident activation of presynaptic NMDA and cannabinoid receptors. Neuron 39:641-654.

Sohya K, Kameyama K, Yanagawa Y, Obta K, Tsumoto T (2007) GABAergic neurons are less selective to stimulus orientation than excitatory neurons in layer II/III of visual cortex, as revealed by in vivo functional $\mathrm{Ca}^{2+}$ imaging in transgenic mice. J Neurosci 27:2145-2149.

Tagawa Y, Kanold PO, Majdan M, Shatz CJ (2005) Multiple periods of functional ocular dominance plasticity in mouse visual cortex. Nat Neurosci $8: 380-388$.

Wang Y, Kakizaki T, Sakagami H, Saito K, Ebihara S, Kato M, Hirabayashi M,
Saito Y, Furuya N, Yanagawa Y (2009) Fluorescent labeling of both GABAergic and glycinergic neurons in vesicular GABA transporter (VGAT)-Venus transgenic mouse. Neuroscience 164:1031-1043.

Wiesel TN, Hubel DH (1963) Single-cell responses in striate cortex of kittens deprived of vision in one eye. J Neurophysiol 26:1003-1017.

Wilson RI, Kunos G, Nicoll RA (2001) Presynaptic specificity of endocannabinoid signaling in the hippocampus. Neuron 31:453-462.

Yoneda T, Watanabe M, Hata Y (2009) Postnatal development of endocannabinoid system in mouse visual cortex. Neurosci Res 62(Suppl. 1):S204.

Zaitsev AV, Povysheva NV, Lewis DA, Krimer LS (2007) P/Q-type, but not $\mathrm{N}$-type, calcium channels mediate GABA release from fast-spiking interneurons to pyramidal cells in rat prefrontal cortex. J Neurophysiol 97:3567-3573.

Zimmer A, Zimmer AM, Hohmann AG, Herkenham M, Bonner TI (1999) Increased mortality, hypoactivity, and hypoalgesia in cannabinoid CB1 receptor knockout mice. Proc Natl Acad Sci U S A 96:5780-5785. 